\title{
PROPERTIES OF LEAD-BISMUTH, LEAD-TIN, TYPE METAL, AND FUSIBLE ALLOYS
}

\author{
By J. G. Thompson
}

\section{ABSTRACT}

The tensile strength, hardness, and elongation of a number of lead alloys have been determined and are presented herewith. Data on the solidification characteristics and on the resistance to compression of some of the alloys also are presented. The alloys studied are divided into four classes: (1) Binary alloys of lead and bismuth, (2) binary alloys of lead and tin, (3) type metals, with and without the addition of small amounts of bismuth, and (4) fusible alloys of bismuth, lead, tin, and cadmium. The data are presented both in tabular form and in graphs.

CONTENTS

I. Introduction

II. Lead-bismuth alloys

1. Methods of test

2. Discussion of results... 1087

3. Summary

III. Lead-tin alloys

IV. Type metals

1. Methods of test

2. Results of tests

3. Additions of 1 to 5 per cent bismuth to stereotype metal _-_ 1099

4. Discussion of results _._.

V. Fusible alloys

VI. Summary ........ 1105

VII. Acknowledgments. 1106

VIII. Bibliography

\section{INTRODUCTION}

In the course of an investigation seeking to develop and extend uses for metallic bismuth and its alloys, conducted at the bureau under the research associate plan in cooperation with the Cerro de Pasco Copper Corporation, the mechanical properties of a number of leadbase alloys were determined. These alloys included lead-bismuth alloys, solders, and type metals with and without additions of bismuth, low-melting alloys, and some miscellaneous alloys. Tensile strength, hardness, and elongation were determined in practically all cases, and are presented in tables and graphs. In addition, the behavior in compression tests and during solidification of some of the alloys is shown. Unfortunately it was not possible to carry to completion the program originally outlined for this cooperative investigation. It has seemed advisable, however, to make available the data secured to those who may be interested even though some of these data are admittedly of a preliminary nature. 


\section{LEAD-BISMIUTH ALLOYS}

Bismuth resembles lead in some of its properties and frequently is associated with lead in its ores. Bismuth, therefore, is encountered as an impurity in the refining of lead, and lead is one of the major impurities encountered in the refining of bismuth. Lead-bismuth alloys, with a wide range of bismuth content could be produced more easily than the highly purified metals. These factors, coupled with the similarity of bismuth to antimony, which is widely used as a hardening agent in lead alloys, made a study of lead-bismuth alloys seem to be a logical starting point in a search for new or useful alloys of bismuth.

Existing information on the properties of bismuth and many of its alloys has been reviewed in a recent circular published by the National Bureau of Standards (7). ${ }^{2}$ The equilibrium diagram of the

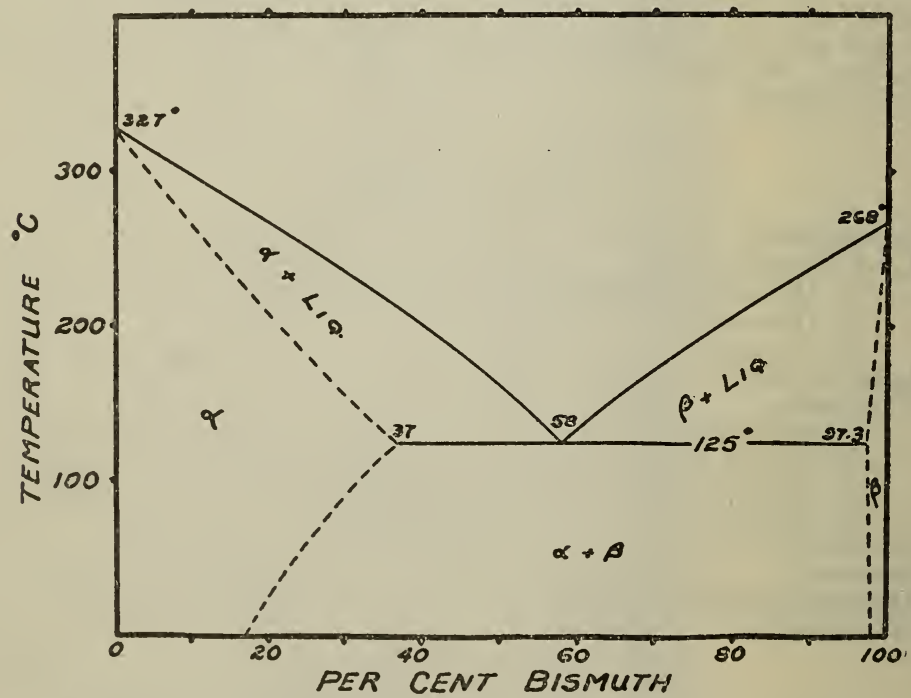

FIgURE 1.-Equilibrium diagram of the system lead-bismuth

(Cowan, Hiers, and Edwards (6).)

bismuth-lead system, according to Cowan, Hiers, and Edwards (6), is shown in Figure 1 and miscellaneous information concerning special characteristics of selected alloys is available in the technical literature. On the other hand, information regarding the hardness or other mechanical properties of bismuth-lead alloys is incomplete, and frequently is contradictory. Di Capua and Arnone (2) found maximum hardness at the eutectic composition while Herold (1) found that the hardness increased steadily to a maximum at about 95 per cent bismuth. Mallock (5) measured the flattening of cones of metal under the application of pressure and concluded that the hardening effect of bismuth on lead is about the same as that of tin, and considerably less than that of antimony. Little information is available concerning other mechanical properties of lead-bismuth alloys. 


\section{METHODS OF TEST}

The determination of the tensile strength, elongation, and hardness of lead-bismuth alloys containing up to about 50 per cent bismuth, therefore, was undertaken. Pure bismuth (99.99 per cent) and pure lead (99.8 per cent) were used in the preparation of the alloys, and numerous analyses showed that the total of impurities in the finished alloys usually was less than 0.2 per cent. Tensile strength and elongation were determined on cast test bars of standard dimensions, 0.505 inch diameter in the reduced section. The test bar mold was made from a split block of mild steel, approximately 3 by 3 by $10 \frac{1}{2}$ inches outside dimensions. Figure 2 shows the interior dimensions of the mold and the provisions for pouring and gating the casting. Hardness was determined on disks sawed from the large ends of the test-bar castings. The usual practice in casting was to preheat the steel mold and to pour the molten metal at the lowest temperature capable of producing good castings. The castings remained in the mold about two minutes and were then removed and allowed to finish cooling in the air. Determination of the properties usually was made 24 hours after casting.

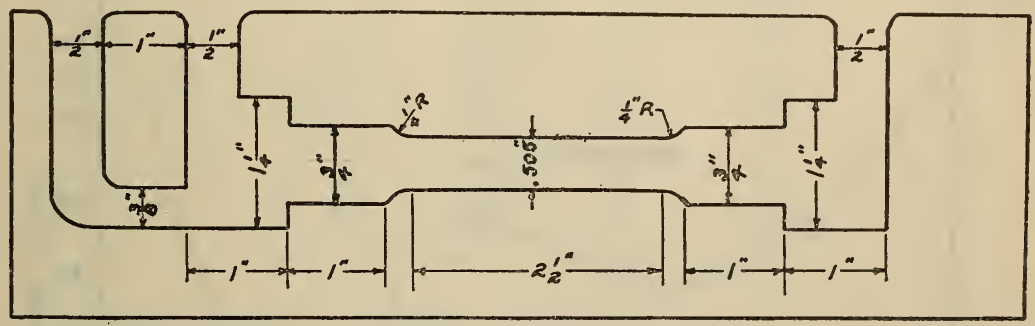

FigURE 2.-Section of test bar mold

All of the lead-bismuth alloys are ductile or plastic with the result that the values obtained for the mechanical properties will depend upon the conditions of the determination. For instance, the apparent tensile strength of an alloy, which contained 52 per cent bismuth, could be varied as desired between 4,000 and 8,000 lbs./in. ${ }^{2}$ depending upon the speed of travel of the head of the testing machine. A rate of operation corresponding to 0.5 inch per minute travel of the free cross head of the testing machine was adopted as standard and was maintained for all determinations.

Brinell hardness was determined using a $10 \mathrm{~mm}$ ball and $100 \mathrm{~kg}$ load, which was applied for one minute. The plastic nature of the alloys presented obstacles in this determination also, but the procedure outlined above generally produced satisfactorily reproducible results. Elongation was determined on a 2 -inch gage length on the tensile specimens, and again the plastic nature of the alloys caused irregularities in the results.

\section{DISCUSSION OF RESULTS}

The data obtained are presented in Table 1 and are shown graphically in Figure 3. The tensile strength of the alloys increases steadily with increasing bismuth content up to 25 per cent. Properties, 
such as the tensile strength, would be expected to change regularly with changing composition up to the limit of solid solubility, but when this limit is passed and the structure of the metal is no longer homogeneous a break in the curve might be expected. Such a break occurs in the tensile strength curve, but it does not occur until a composition of 25 per cent bismuth is reached. If equilibrium conditions existed in the specimens, this would indicate that bismuth is

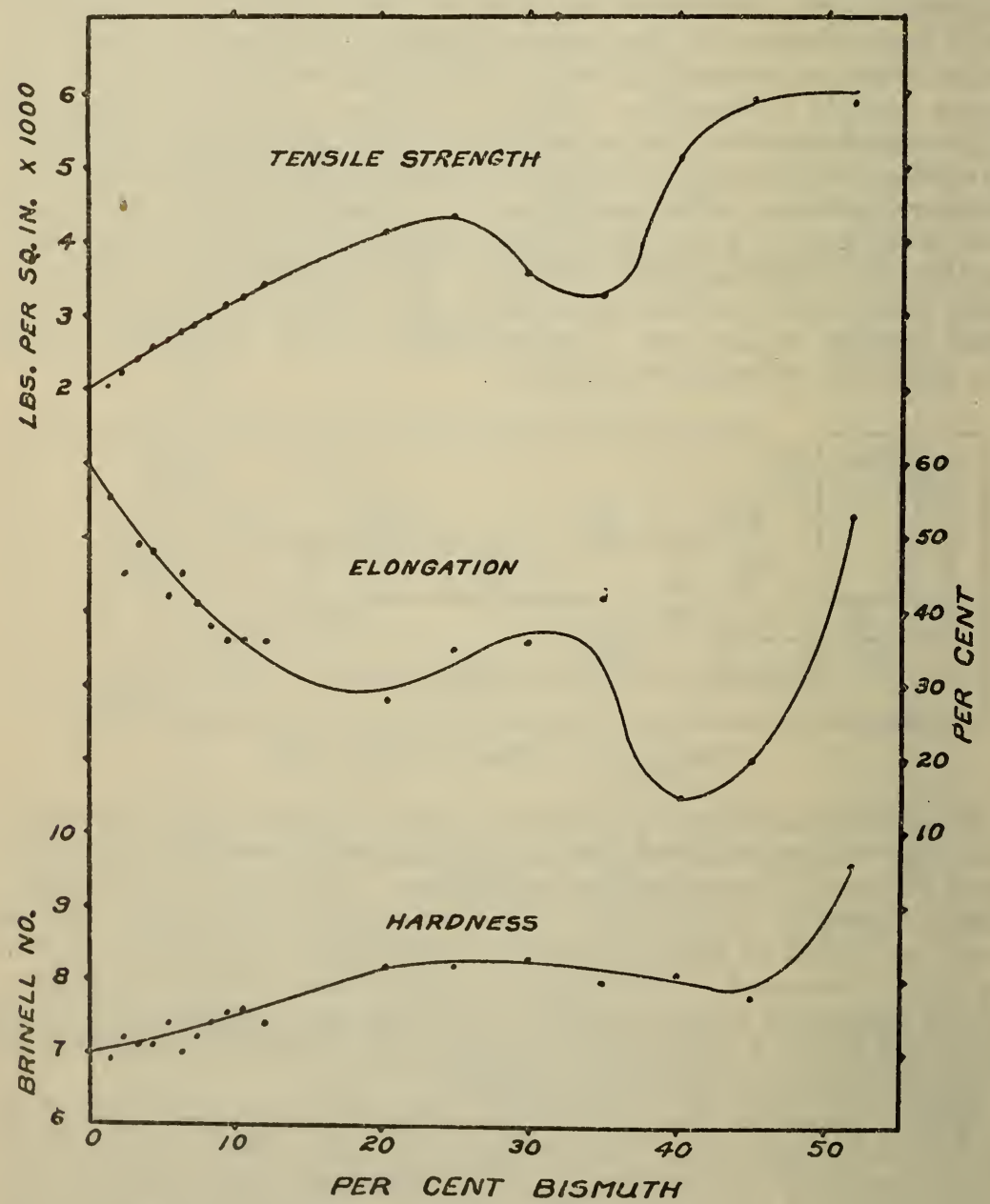

FIGURE 3.-Mechanical properties of lead-bismuth alloys

soluble in solid lead at room temperature to the extent of 25 per cent instead of to 17 per cent as indicated in the equilibrium diagram. It is possible, however, that some, if not all, of these discrepancies were caused by the fact that the rather bulky cast specimens did not attain equilibrium at room temperature in the time available for these experiments. From 25 to 35 per cent bismuth, precipitation of increasing amounts of bismuth or a bismuth-rich constituent destroys the uniformity and decreases the strength of the solid solution 
of bismuth in lead. From 35 to 50 per cent bismuth, the tensile strength again increases indicating that the bismuth-rich constituent when present in appreciable amounts increases the tensile strength, although when present in lesser amounts or as an impurity it has the opposite effect. In general, the curve shows a gradual increase in tensile strength with increasing bismuth up to 52 per cent, except for irregularities in the region of 30 and 35 per cent bismuth.

TABLE 1.-Mechanical properties of lead-bismuth alloys in the cast condition

\begin{tabular}{|c|r|r|r|}
\hline Bismuth & $\begin{array}{r}\text { Tensile } \\
\text { strength }\end{array}$ & $\begin{array}{c}\text { Brinell } \\
\text { hardness } \\
\text { number }\end{array}$ & $\begin{array}{r}\text { Elongation } \\
\text { in 2 inches }\end{array}$ \\
\cline { 1 - 2 } Per cent & Lb./in.2 & & Per cent \\
0 & 2,030 & 7.0 & 65 \\
1.4 & 2,030 & 6.9 & 55 \\
2.35 & 2,200 & 7.2 & 45 \\
3.35 & 2,400 & 7.1 & 49 \\
4.38 & 2,570 & 7.1 & 48 \\
5.45 & 2,675 & 7.4 & 42 \\
6.35 & 2,780 & 7.0 & 45 \\
7.43 & 2,880 & 7.2 & 41 \\
8.44 & 2,990 & 7.4 & 38 \\
9.50 & 3,120 & 7.55 & 36 \\
& & & \\
10.59 & 3,240 & 7.6 & 36 \\
12.15 & 3,420 & 7.4 & 36 \\
20.3 & 4,127 & 8.2 & 28 \\
24.8 & 4,353 & 8.2 & 35 \\
29.7 & 3,547 & 8.3 & 36 \\
35.0 & 3,277 & 8.0 & 42 \\
40.1 & 5,150 & 8.1 & 15 \\
45.1 & 5,917 & 7.8 & 20 \\
51.8 & 5,890 & 9.6 & 53 \\
\hline
\end{tabular}

The experimental data show a gradual decrease of elongation with increasing bismuth content, then irregularity in the same region of the limit of solid solubility, and a final rise after the solid solubility is definitely exceeded. Elongation results on cast specimens tend to be irregular as they are influenced by minor imperfections in the castings to a greater degree than are either the tensile strength or hardness.

The hardness data show an increase in hardness with increasing bismuth up to about 20 per cent, followed by practically constant values from 20 to 45 per cent, with a final rise at the end of the curve. Irregularities in the region of 30 and 35 per cent are not so pronounced as in the other curves.

A few experiments on the susceptibility of these alloys to heat treatment or to precipitation hardening were performed. Standard 0.505 -inch test bars were examined in the following conditions: As cast; cast and aged at room temperature; quenched in ice water from $120^{\circ} \mathrm{C}$. and pulled immediately; quenched in ice water and aged 24 hours; and annealed by heating to $120^{\circ} \mathrm{C}$. for two hours, followed by slow cooling to room temperature. No significant differences were established between the "as cast" and the "cast and aged at room temperature" specimens during periods of aging extending up to seven months. The results of the tensile strength determinations on these heat-treated specimens are shown graphically in Figure 4. No appreciable variation in results, below 35 per cent bismuth, 
was caused by any of the hoat treatments used, probably because the test bars, 0.505 inch minimum diameter, were not so responsive to heat treatments as were the fine wires used by Dean and his coworkers $(3,4)$ in their investigations of lead-antimony alloys. Above 35 per cent bismuth the effects of heat treatment are more noticeable.

Specimens quenched in ice water, from $120^{\circ} \mathrm{C}$., and pulled immediately, show practically the same tensile strength as fully annealed specimens. Their strength, however, is definitely less than that of either the "as cast" or of the "quenched and aged 24 hours" specimens. This would indicate the same tensile strength for the quenched solid solution and for the fully annealed material in which the excess bismuth-rich constituent has precipitated and agglomerated. The

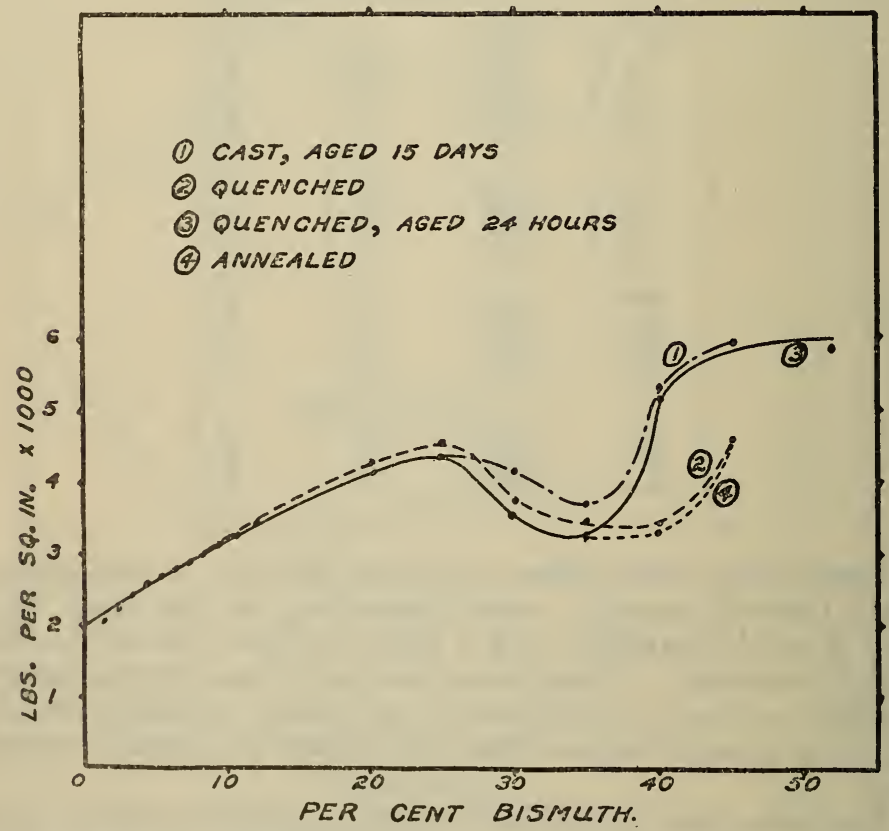

Figune 4.-Effect of heat treatment and aging on the mechanical properties of lead-bismuth alloys

quenched solid solution is unstable at room temperature, precipitation of the excess bismuth occurs and the presence of this precipitate in a fincly divided condition, not agglomerated as it is in the annealed state, stiffons and strengthens the alloy. This precipitation is practically complete in 24 hours at room temperature.

\section{SUMMARY}

The acidition of bismuth to lead hardens and stiffens the resultant alloys. 'The effects throughout the range from 0 to 50 per cent bismuth are roughly proportional to the concentration of bismuth, except for irregularities in the region of the limit of solid solubility of bismuth in lead. 'This hardening effect of bismuth on lead is less than that developed by equal proportions of antimony as was shown by the fact that all of the lead-bismuth alloys up to and including the 12 per cent 
alloy were readily rolled to sheets one thirty-second inch thick. From the ease with which even the 12 per cent alloy was rolled, it appears that sheets containing considerably more than 12 per cent bismuth could be prepared, but this was not attempted in the present investigation.

Lead-bismuth alloys, in the form of comparatively bulky test bars, do not exhibit the age hardening and susceptibility to heat treatment,

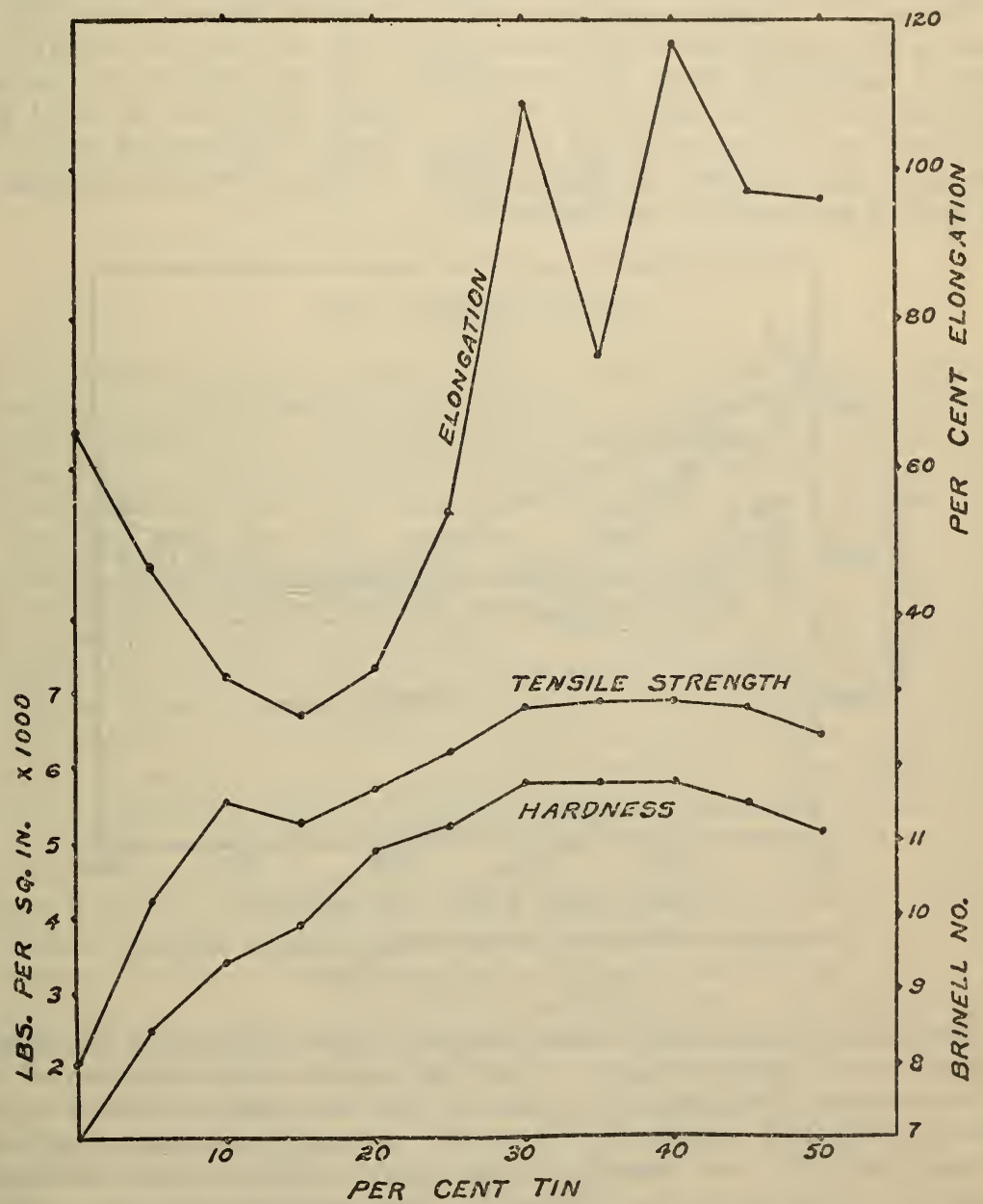

FIGURE 5.-Mechanical properties of lead-tin alloys

throughout the range of limited solid solubility, which has been demonstrated for lead-antimony alloys. Fine wires of lead-bismuth alloys might be more susceptible to heat treatment and might show effects comparable to those obtained for lead-antimony wires.

\section{LEAD-TIN ALLOYS}

The mechanical properties of lead-tin alloys, containing up to 50 per cent tin, were determined and are presented in Table 2 and in Figure 5. These data were intended to serve as a base for an in- 
vestigation of the possible use of bismuth in soft solders, a use which is at once suggested by the known ability of bismuth to lower the melting point of metallic alloys and to decrease the surface tension of lead and tin.

The freezing points, solidification ranges, and limits of solid solubility of the lead-tin alloys may be obtained from equilibrium diagrams, such as that of Cowan, Hiers, and Edwards (8), reproduced in Figure 6. Experimental data of the present investigation (fig. 5) show a distinct parallelism between the hardness and tensile strength curves, although there are irregularities in the region of limited solubility of tin in lead, $i$. e., in the region below 16 per cent tin. Both curves rise steadily as the tin content is increased up to 30 per cent, then flatten and finally begin to drop off as compositions of 45 and 50 per cent tin are reached.

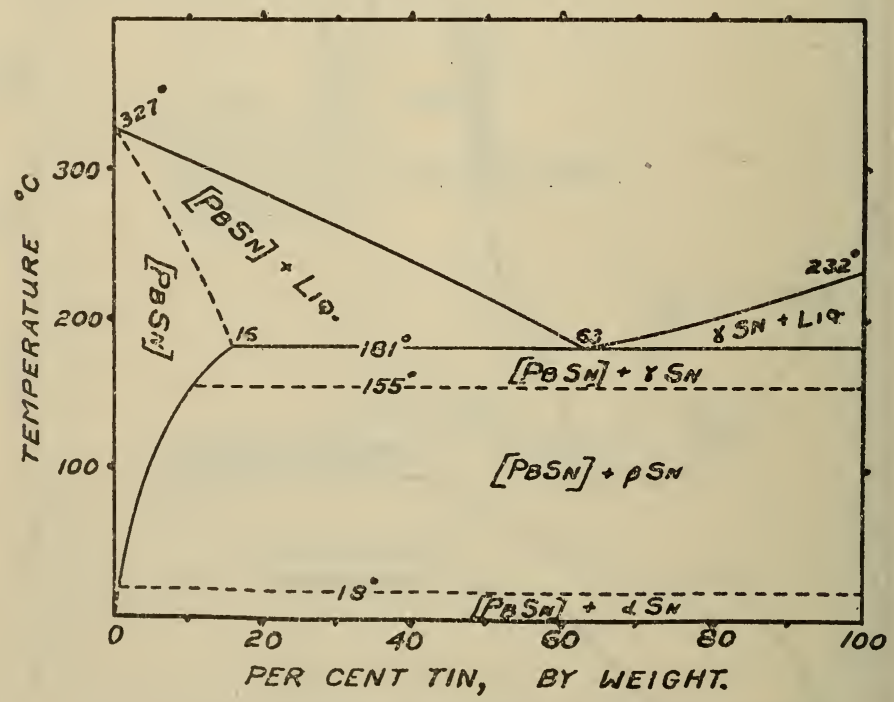

FIGURE 6.-Equilibrium diagram of the system lead-tin

(Cowan, Hiers, and Edwaràs (8).)

Elongation data exhibit more variations than appear in the tensile strength and hardness data. The first effect of the addition of tin is to decrease the elongation values, until a sharp minimum in the curve is reached at about 15 per cent tin, approximately the limit of solid solubility at eutectic temperature. As the tin is increased beyond 15 per cent, the elongation rises rapidly to values greater than 100 per cent and remains at or near 100 per cent until 50 per cent tin is reached. Some irregularity is evident in these high elongation values, but these irregularities are believed to be more experimental errors than significant variations in the properties of the alloys. Determinations usually were limited to three test bars of each composition and elongation results are especially susceptible to minor defects in the cast specimens.

An interesting feature of these three curves is the uniformly high tensile strength, hardness, and elongation of all alloys between 30 and 40 per cent tin, 
TABLE 2.-Mechanical properties of lead-tin alloys in the cast condition

\begin{tabular}{|c|c|c|c|c|}
\hline \multicolumn{2}{|c|}{ Composition } & \multirow{2}{*}{$\begin{array}{l}\text { Tensile } \\
\text { strongth }\end{array}$} & \multirow{2}{*}{$\begin{array}{l}\text { Brinnel } \\
\text { hardness } \\
\text { number }\end{array}$} & \multirow{2}{*}{$\begin{array}{l}\text { Elongation } \\
\text { in } 2 \text { inches }\end{array}$} \\
\hline $\mathrm{Pb}$ & Sn & & & \\
\hline $\begin{array}{c}\text { Per cent } \\
100 \\
95 \\
90 \\
85 \\
80 \\
75\end{array}$ & $\mid \begin{array}{c}\text { Per cent } \\
0 \\
5 \\
10 \\
15 \\
20 \\
25\end{array}$ & $\begin{array}{r}\text { Lb./in. }{ }^{2} \\
2,030 \\
4,220 \\
5,560 \\
5,270 \\
5,730 \\
6,220\end{array}$ & $\begin{array}{r}7.0 \\
8.5 \\
9.4 \\
9.9 \\
10.9 \\
11.2\end{array}$ & $\begin{array}{r}\text { Per cent } \\
65 \\
47 \\
32 \\
27 \\
33 \\
54\end{array}$ \\
\hline $\begin{array}{l}70 \\
65 \\
60 \\
55 \\
50\end{array}$ & $\begin{array}{l}30 \\
35 \\
40 \\
45 \\
50\end{array}$ & $\begin{array}{l}6,810 \\
6,880 \\
6,890 \\
6,800 \\
6,400\end{array}$ & $\begin{array}{l}11.8 \\
11.8 \\
11.8 \\
11.5 \\
11.1\end{array}$ & $\begin{array}{r}109 \\
75 \\
117 \\
97 \\
96\end{array}$ \\
\hline
\end{tabular}

\section{TYPE METALS}

The statement that bismuth has been used in type metals is found repeatedly in the literature of bismuth (7). An essential characteristic of type metals is that they shall make exact reproductions of the type molds, and a frequent explanation for the use of bismuth is that alloys containing bismuth produce good castings because they expand on freezing and that this property, already present in the leadantimony alloys, is improved by additions of bismuth. Matuyama (10) proved that this is not the proper explanation for the ability of type metals to produce good castings. Pure antimony expands during solidification and lead-antimony alloys rich in antimony expand, but to a lesser extent, than does pure antimony. This expansion decreases as the antimony content decreases until at about 75 per cent antimony an alloy is obtained which passes from the liquid to the solid state without change in volume. Below 75 per cent antimony, solidification of the alloys is accompanied by shrinkage which increases in amount as the composition approaches pure lead. In a similar manner bismuth-rich alloys expand, but low-bismuth alloys contract during solidification (9). Matuyama showed that lead-antimony and leadantimony-tin alloys, containing from 12 to 16 per cent antimony, all contract 2 per cent or more during solidification. He ascribes the excellent casting properties of type metals to their low surface tension in the molten state, which promotes accurate reproduction of the contour of the mold, and to the fact that castings of type metal are usually made under pressure. Normal type metals, therefore, do not expand during solidification but the tradition that they do expand is still encountered frequently.

The fact remains that type metal alloys which consist essentially of lead, antimony, and tin, produce remarkably good castings. The primary requirement of a good type metal is that it shall produce good castings under the conditions of operation of the casting machine employed in that type of work. Desirable features are hardness, strength, resistance to compression and to wear, but these are all secondary in importance to the "casting properties" under the fixed conditions of operation of a given machine.

Bismuth resembles antimony in its ability to harden alloys of lead and tin, although it is not as efficient as antimony in this respect. 
Bismuth also lowers the surface tension of molten lead and lowers the solidification points of lead and its alloys. Formulas are given in the literature (7) for type metals in which tin has been completely replaced by bismuth, as much as 29 per cent bismuth being used in one case. Normal type metals to which have been added small amounts of bismuth, 1 to 5 per cent, seemed a more promising field for investigation. Additional interest in this field was occasioned by the statement in a private communication that the best British stereotype metal contains 1 per cent of bismuth, although no reason for the presence of bismuth was given.

For these reasons it was decided to study the effect of additions of from 1 to 5 per cent bismuth on the properties of type metals. As a base for this work a number of samples of commercial type metals were obtained and their tensile strength, hardness, elongation, freezing characteristics, and resistance to compression were observed.

\section{METHODS OF TEST}

Tensile strength and elongation of the type metal alloys were determined on test bars, 0.505 inch in diameter, cast in a heavy steel mold as described for the lead-bismuth alloys. The bars were pulled at a uniform rate, 0.5 inch per minute, as in the experiments previously described. Hardness was determined on disks cut from the enlarged ends of the test-bar castings. It was recognized that test bars cast in this way probably would not duplicate the tensile strength and hardness ef actual linotype and monotype castings where the metal is cast in thin sections and is chilled rapidly. However, the use of the test-bar mold approximates roughly the conditions under which type metal is cast, and allows direct comparison of stereotype with linotype and monotype metals which in actual practice are cast under decidedly different conditions.

Solidification temperatures were obtained by means of mercury thermometers. Graphite crucibles approximately $1 \frac{112}{2}$ inches in internal diameter and 5 inches deep were used. Enough metal to cover the immersion mark on the stem of the thermometer, usually about $800 \mathrm{~g}$, was melted and superheated to the desired degree. The hot crucible was removed from the furnace, placed on a brick or an asbestos plate, and allowed to cool in the air. Readings of the thermometer were taken at half-minute intervals and the molten metal was stirred continuously by means of the thermometer until solidfication of the melt made further stirring impossible. Crystals of metal sometimes formed on the thermometer bulb, and the resultant insulating action caused irregularities in the readings, but with constant stirring this difficulty usually was avoided and results were satisfactorily reproducible. The glass thermometers devitrified fairly rapidly at temperatures over $300^{\circ} \mathrm{C}$., but at least a dozen sets of readings ordinarily could be obtained before a thermometer was seriously affected.

Many difficulties were encountered in attempts to secure satisfactory compression data. The results obtained varied widely with the dimensions of the specimen, the rate of loading, and the time the load was maintained. For a given setting of the control valve on the Amsler testing machine, appreciable variations in the speed of travel of the crosshead were observed, depending upon room temperature, 
amount of previous use of the machine on that particular day, and any other factors which affected the fluidity of the oil. The variations were particularly noticeable at the low speeds $(0.05$ inch or less per minute) used for compression tests. The procedure finally adopted was to prepare cast rods $1 \frac{1}{1} 8$ inches in diameter and about 4 inches long. These were cut in a lathe to specimens 1 inch long: ( \pm 0.01 inch), with parallel faces, in accordance with the American Society for Testing Materials specifications for compression tests of soft metals. The cylindrical surface of each specimen was not machined but was left in the cast condition. A specimen was placed in the Amsler machine and a predetermined load slowly applied and ' held for one minute. After the release of the load the permanent deformation of the specimen was measured by means of micrometer

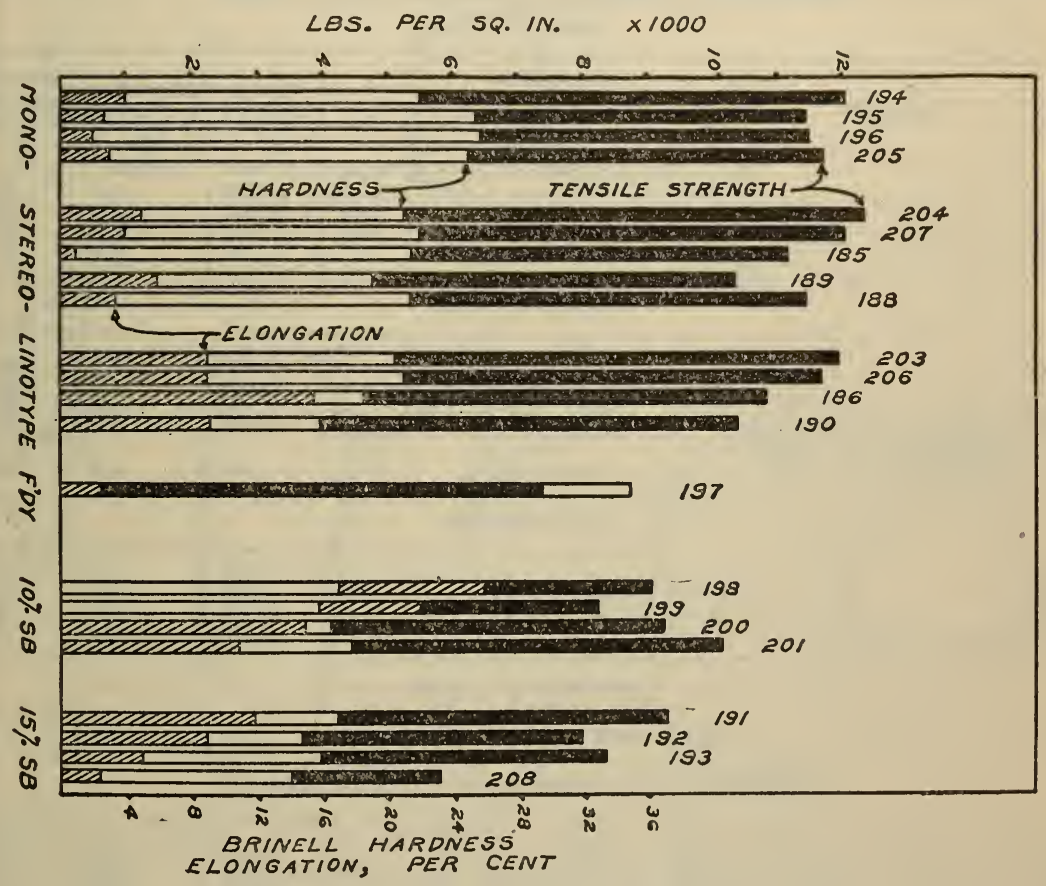

Figure 7.-Mechanical properties of type metals

calipers. The operation was repeated with another specimen, at a different load, until enough readings below 2 per cent deformation were obtained to plot a curve. The method admittedly is rough, but the length of time the load was maintained appears to be enough to neutralize variations in the rate of loading and the results could be duplicated with reasonable accuracy.

\section{RESULTS OF TESTS}

The composition of the type metals and the results obtained in the tensile strength, hardness and elongation determinations are presented in Table 3 and in Figure 7. Monotype metals, containing 15 to 19 per cent antimony and 7 to 10 per cent tin, are the hardest of the specimens studied except for the foundry type which contained 2 
per cent copper. Stereotype metals, lower in antimony and in tin than the monotypes, are less hard and of somewhat greater tensile strength. Linotype metals, containing 11.5 per cent antimony and about 4 per cent tin, are still softer and somewhat lower in tensile strength. The elongation data obtained are somewhat irregular, but, in general, the per cent elongation increases as the hardness and tensile strength decrease. Alloys 189 and 190 show that the addition of 5 per cent bismuth to stereotype 185 and to linotype 186 decreases the tensile strength and hardness in each case. However, if a synthetic alloy (188) is made up to duplicate 189 without the arsenic and copper which are present in the latter, higher tensile strength and hardness values are obtained.

TABLE 3.-Mechanical properties of type metals MONOTYPES

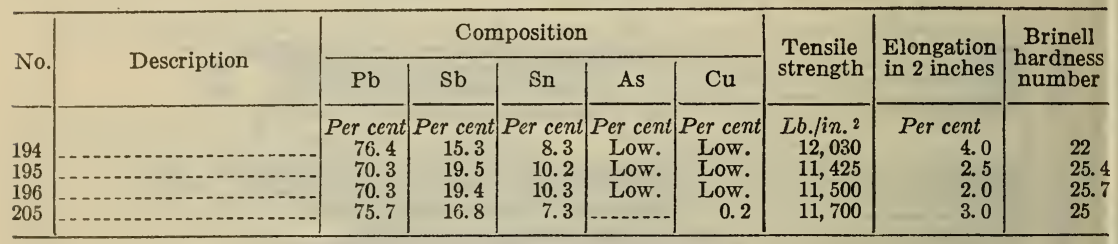

STEREOTYPES

\begin{tabular}{|c|c|c|c|c|c|c|c|c|c|}
\hline \multirow{5}{*}{$\begin{array}{l}204 \\
207 \\
185 \\
189 \\
188\end{array}$} & & & \multirow{4}{*}{$\begin{array}{l}13.0 \\
14.0\end{array}$} & \multirow{4}{*}{$\begin{array}{l}6.5 \\
5.3\end{array}$} & \multirow{4}{*}{0.06} & \multirow{4}{*}{$\begin{array}{r}0.18 \\
.01\end{array}$} & \multirow{4}{*}{$\begin{array}{l}12,380 \\
12,050 \\
11,190 \\
10,350\end{array}$} & \multirow{4}{*}{$\begin{array}{l}5.0 \\
4.0 \\
1.0 \\
6.0\end{array}$} & \multirow{4}{*}{$\begin{array}{l}21 \\
22 \\
21 \\
19\end{array}$} \\
\hline & & \multirow{3}{*}{$\begin{array}{l}80.3 \\
80.6\end{array}$} & & & & & & & \\
\hline & & & & & & & & & \\
\hline & $185+5$ per cent $\mathrm{Bi}$ & & & & & & & & \\
\hline & $\begin{array}{l}\text { Synthetic } 185+5 \text { per } \\
\text { cent } \mathrm{Bi}\end{array}$ & \multicolumn{5}{|c|}{ (No As nor $\mathrm{Cu}$ ) } & 11,470 & 3.5 & 21.6 \\
\hline
\end{tabular}

LINOTYPES

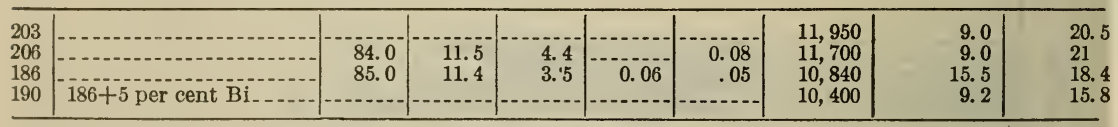

FOUNDRY TYPE

\begin{tabular}{l|l|l|l|l|l|l|l|l}
\hline 197 & 61.0 & 25.0 & 12.0 & $\ldots \ldots .$. & 2.0 & 7,390 & 2.5 & 35 \\
\hline
\end{tabular}

SYNTHETIC TYPE METALS (10 PER CENT Sb)

\begin{tabular}{|c|c|c|c|c|c|c|c|c|c|}
\hline $\begin{array}{l}198 \\
199 \\
200 \\
201\end{array}$ & $\begin{array}{l}-2 \\
-2\end{array}$ & $\begin{array}{l}90.0 \\
85.0 \\
82.5 \\
80.0\end{array}$ & $\begin{array}{l}10.0 \\
10.0 \\
10.0 \\
10.0\end{array}$ & $\begin{array}{r}. \\
2.5 \\
5.0\end{array}$ & $\begin{array}{l}B i \\
-5.0 \\
5.0 \\
5.0\end{array}$ & 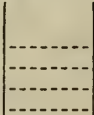 & $\begin{array}{r}9,080 \\
8,220 \\
9,270 \\
10,150\end{array}$ & $\begin{array}{l}26.0 \\
22.0 \\
15.0 \\
11.0\end{array}$ & $\begin{array}{l}17 \\
15.8 \\
16.5 \\
17.8\end{array}$ \\
\hline
\end{tabular}

SYNTIETIC TYPE METALS (15 PER CENT Sb)

\begin{tabular}{|c|c|c|c|c|c|c|c|c|c|}
\hline $\begin{array}{l}191 \\
192 \\
193 \\
208\end{array}$ & 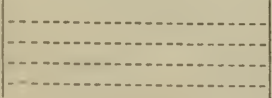 & $\begin{array}{l}85.0 \\
80.0 \\
77.5 \\
70.0\end{array}$ & $\begin{array}{l}15.0 \\
15.0 \\
15.0 \\
15.0\end{array}$ & $\begin{array}{r}-7.5 \\
-\end{array}$ & $\begin{array}{r}5.0 \\
5.0 \\
15.0\end{array}$ & - & $\begin{array}{l}9,300 \\
8,000 \\
8,370 \\
5,810\end{array}$ & $\begin{array}{r}11.7 \\
9.0 \\
5.2 \\
2.3\end{array}$ & $\begin{array}{l}17 \\
14.8 \\
15.8 \\
14.2\end{array}$ \\
\hline
\end{tabular}

ADDITION OF BISMUTII TO STEREOTYPE NO. 207

\begin{tabular}{|c|c|c|c|c|c|c|c|c|}
\hline $\begin{array}{l}207 \\
2\left(y^{\prime}\right) \\
210 \\
211 \\
212 \\
213\end{array}$ & $\begin{array}{l}207+1 \text { per cent } \mathrm{Bi}- \\
207+2 \text { per cent } \mathrm{Bi}- \\
207+3 \text { per cent } \mathrm{Bi}- \\
207+4 \text { per cont } \mathrm{Bi}- \\
207+5 \text { per cent } \mathrm{Bi} .\end{array}$ & 80.3 & $\begin{array}{r}13.0 \\
-1.0 \\
-10\end{array}$ & 6.5 & $\begin{array}{r}0.18 \\
0 \\
0\end{array}$ & $\begin{array}{l}12,050 \\
11,150 \\
11,200 \\
10,800 \\
10,600 \\
10,300\end{array}$ & $\begin{array}{l}4.0 \\
4.0 \\
8.5 \\
5.5 \\
5.5 \\
4.5\end{array}$ & $\begin{array}{l}22 \\
21 \\
21 \\
21.5 \\
20 \\
19.4\end{array}$ \\
\hline
\end{tabular}

In the series of synthetic alloys which contained 10 per cent antimony without arsenic or copper, the addition of 5 per cent bismuth 
lowered the tensile strength, but the addition of 2.5 per cent tin increased the strength above the original value, and 5 per cent tin further increased the strength. All of these additions lowered the ductility of the original lead-antimony alloy but the hardness was not affected appreciably. Similar results were obtained for the synthetic alloys which contained 15 per cent antimony. The addition of 5 per cent bismuth lowered the tensile strength, but this was partially corrected by the addition of 2.5 per cent tin. The elongation of the lead-antimony alloy is lowered by additions of either bismuth or tin but the hardness is not affected to any great extent. Alloy No. 208, which contained 70 per cent lead, 15 per cent antimony, and 15 per cent bismuth, represents one of the compositions

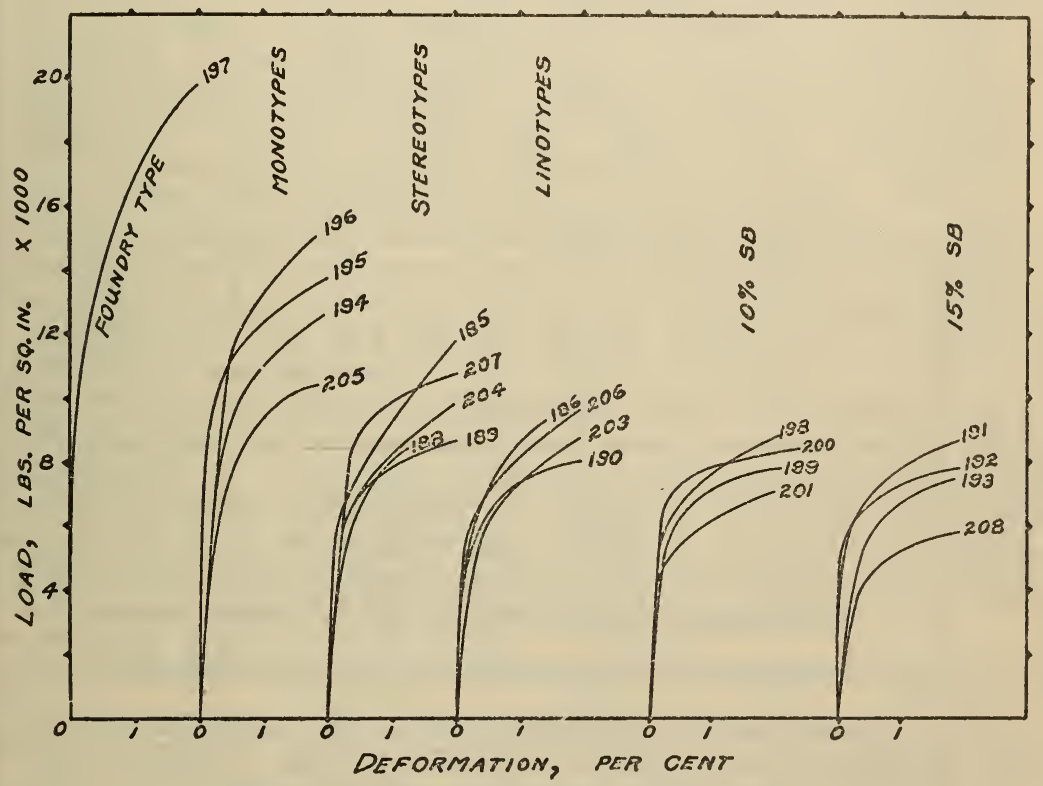

FIGURE 8.-Compression tests on type metals

which, according to the literature, have been used as type metals. Its mechanical properties are decidedly inferior to those of modern type metals.

The compression data (fig. 8 and Table 4), in general, run parallel to the hardness data. Very few of the specimens examined showed any signs of fracture in a compression test. Most of them begin to flow at relatively low pressures. At pressures above 5,000 lbs./in. ${ }^{2}$ the flow usually is continuous as long as the load is applied. No compression yield point could be obtained and true elasticity if present at all, exists only at very low pressures. The foundry type metal high in copper showed the greatest resistance to compression; the monotype, stereotype, and linotype metals were progressively less resistant. The synthetic alloys were about as resistant to compression as the linotype and stereotype metals except for No. 208, which was inferior to the others in compression strength as in other mechanical properties. These compression data confirm the results obtained in other mechanical tests. 


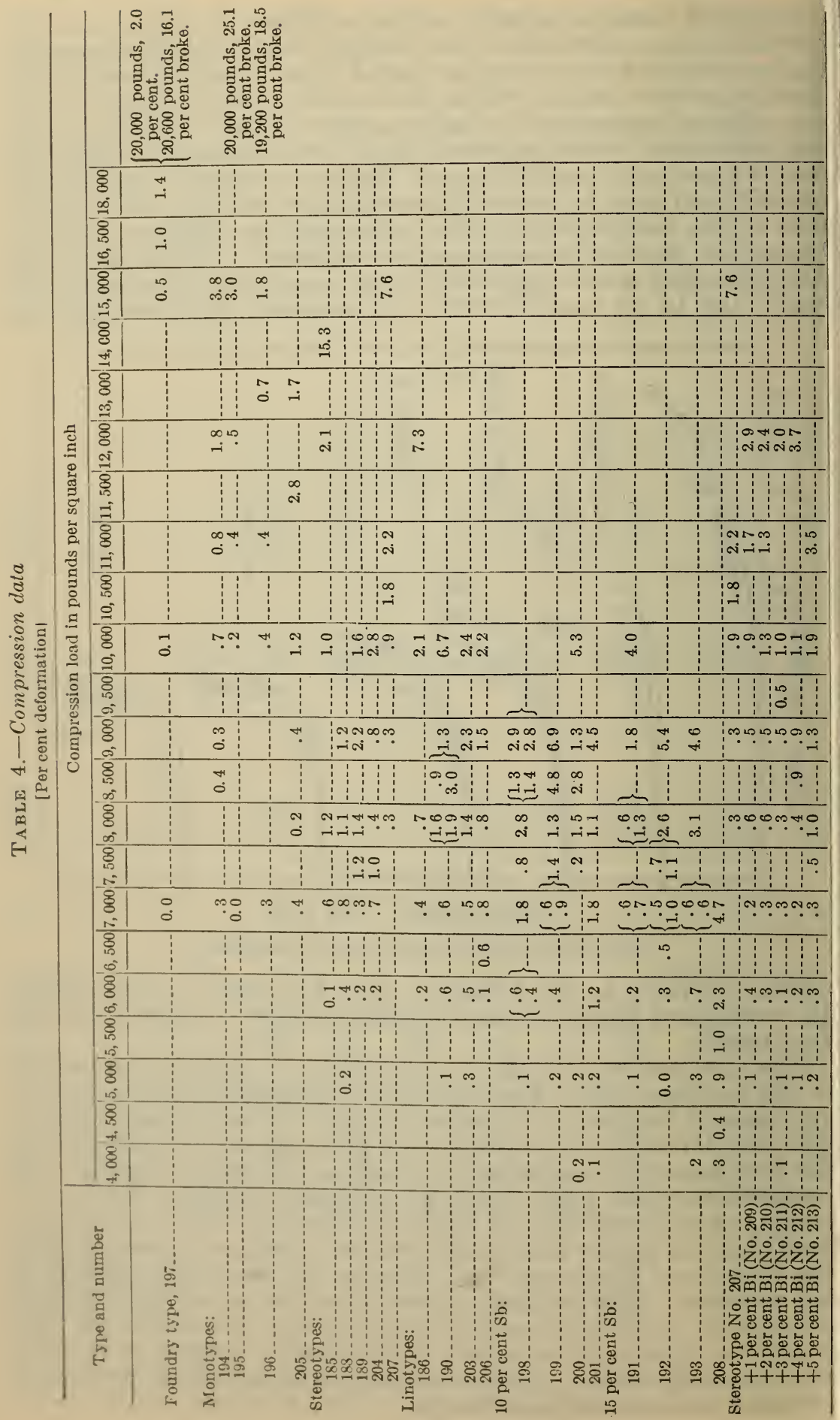


The cooling curves of the commercial and of the modified type metal alloys are shown in Figure 9. All of the type metals in the absence of bismuth show the beginning of final solidification at or near $242^{\circ} \mathrm{C}$. The shape of the cooling curves below this point is affected by several factors, such as the quantity of metal present and the point where stirring is discontinued. The importance of some of these factors was not fully appreciated in early experiments. Consequently, some of the curves, for example No. 206, indicate the presence of appreciable amounts of a eutectic mixture, whereas others, for example Nos. 185, 194, and 195, resemble the curves obtained for solid solutions. In all cases, solidification is complete within about $5^{\circ}$ of the point where the melt becomes decidedly mushy with precipitated crystals. The point where the alloy becomes completely molten, or where crystals first appear on cooling, varied with the composition of the metal. Alloy No. 197, on cooling, began to develop crystals at or above $300^{\circ} \mathrm{C}$, which is considerably higher than the initial crystallization point of the other alloys. This would be expected from the fact that No. 197 contains 2 per cent copper, considerably more than is present in any of the other alloys.

Nos. 188, 189, and 190 show that the addition of 5 per cent bismuth to stereotype or linotype metal lowers the final solidification point, or range, some $8^{\circ}$ or $9^{\circ}$ to about $233^{\circ} \mathrm{C}$. An alloy which contained 15 per cent bismuth, No. 208, did not begin to solidify until a temperature of $217^{\circ} \mathrm{C}$. was reached.

In the synthetic alloys, the addition of 5 per cent bismuth lowers the freezing point of both the 10 and 15 per cent antimony alloys approximately $10^{\circ}$. Addition of tin to these alloys lowers the freezing point still further. The break in the pure antimony-lead curves comes at temperatures slightly higher than in the type metal curves. This shows the effect of the tin and other elements in the type metals, on the freezing points of the binary lead-antimony alloys.

\section{ADDITIONS OF 1 TO 5 PER CENT BISMUTH TO STEREOTYPE METAL}

In order to observe the effect of bismuth in more detail, additions of $1,2,3,4$, and 5 per cent bismuth were made to stereotype metal No. 207. The effects of these additions are shown in Tables 3 and 4 and in Figures 10 and 11. The hardness, tensile strength, and resistance to compression decrease fairly regularly throughout this range of composition. Elongation results again are irregular, but in general do not change greatly with changing compositions. The apparent sudden rise in elongation at 2 per cent bismuth is open to question.

The cooling curves for this series of alloys containing added bismuth (fig. 11) were made with more attention to detail than in some of the preceding determinations. Each curve shows three distinct points, (1) the change in slope of the upper portion of the curve which indicates the beginning of crystallization, (2) the abrupt change in the slope of the curve which indicates the beginning of final solidification, and (3) the point where the solidification is complete and the curve again becomes a straight or nearly straight line. The temperatures for these three points are indicated on each curve. It is evident that crystallization begins at temperatures of $255^{\circ}$ to $260^{\circ} \mathrm{C}$. and this temperature of first crystallization is not appreciably affected by the presence of bismuth. The beginning of final solidification, however, 


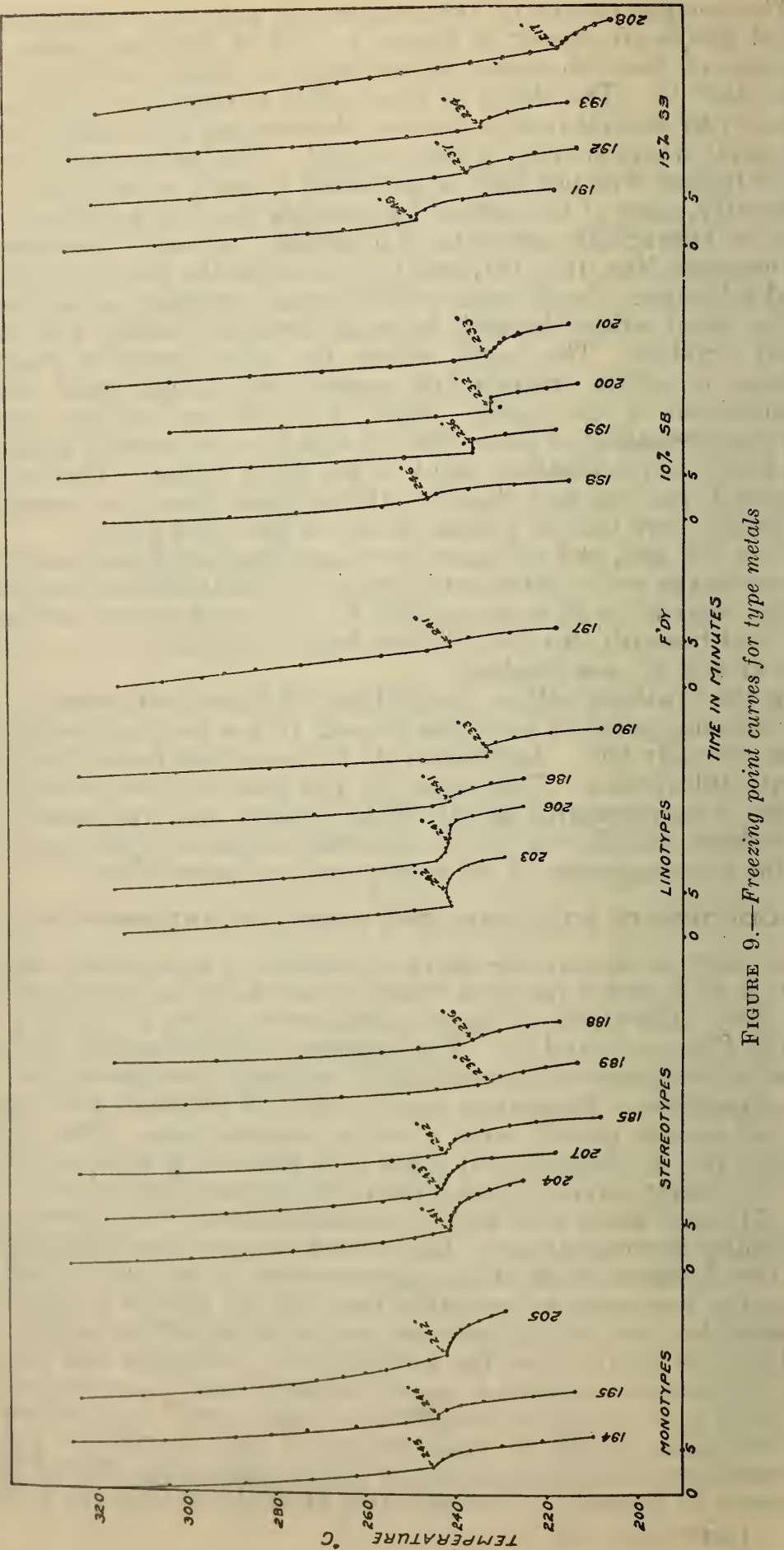


decreases regularly as bismuth is added, from $243^{\circ} \mathrm{C}$. for the original type metal to $235^{\circ} \mathrm{C}$. for the alloy which contained 5 per cent bismuth. The freezing range is affected to a still greater extent. The original stereotype metal is solid at $237^{\circ}$ C., $6^{\circ}$ below the point of initial solidification. When 5 per cent bismuth is added solidification begins at $235^{\circ} \mathrm{C}$., and is not complete until the temperature drops

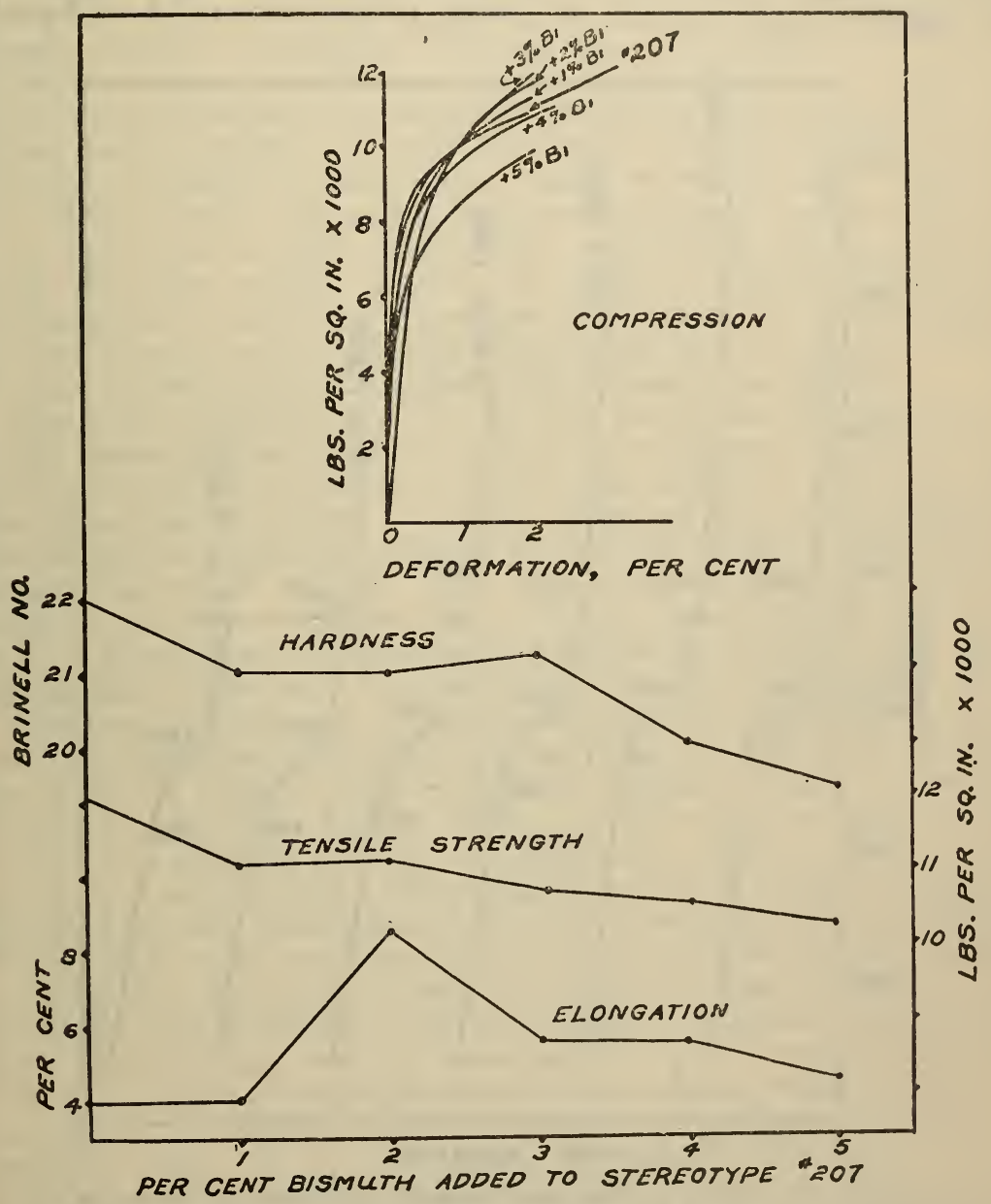

FIGURE 10.-Effect of additions of bismuth on the mechanical properties of a stereotype metal

to $222^{\circ}$ C., a range of $13^{\circ}$. This effect of bismuth also is evident in the gradual rounding off of the shoulder of the solidification arrest, as the bismuth content increases.

\section{DISCUSSION OF RESULTS}

Data and curves have been prepared to show the mechanical properties of several type metals and of the effects of additions of bismuth on these properties. It is evident from these data that addi- 
tions of bismuth tend to decrease slightly the tensile strength, hardness, and resistance to compression of type metals. However, in the preparation of these alloys it appeared that when bismuth was present the castings filled the mold more completely. In other words, it appeared that the "casting properties" of type metals, perhaps, were improved by the presence of bismuth. Type metals now in use produce remarkably good castings, but further improvement is possible. If this apparent improvement in casting properties could be definitely

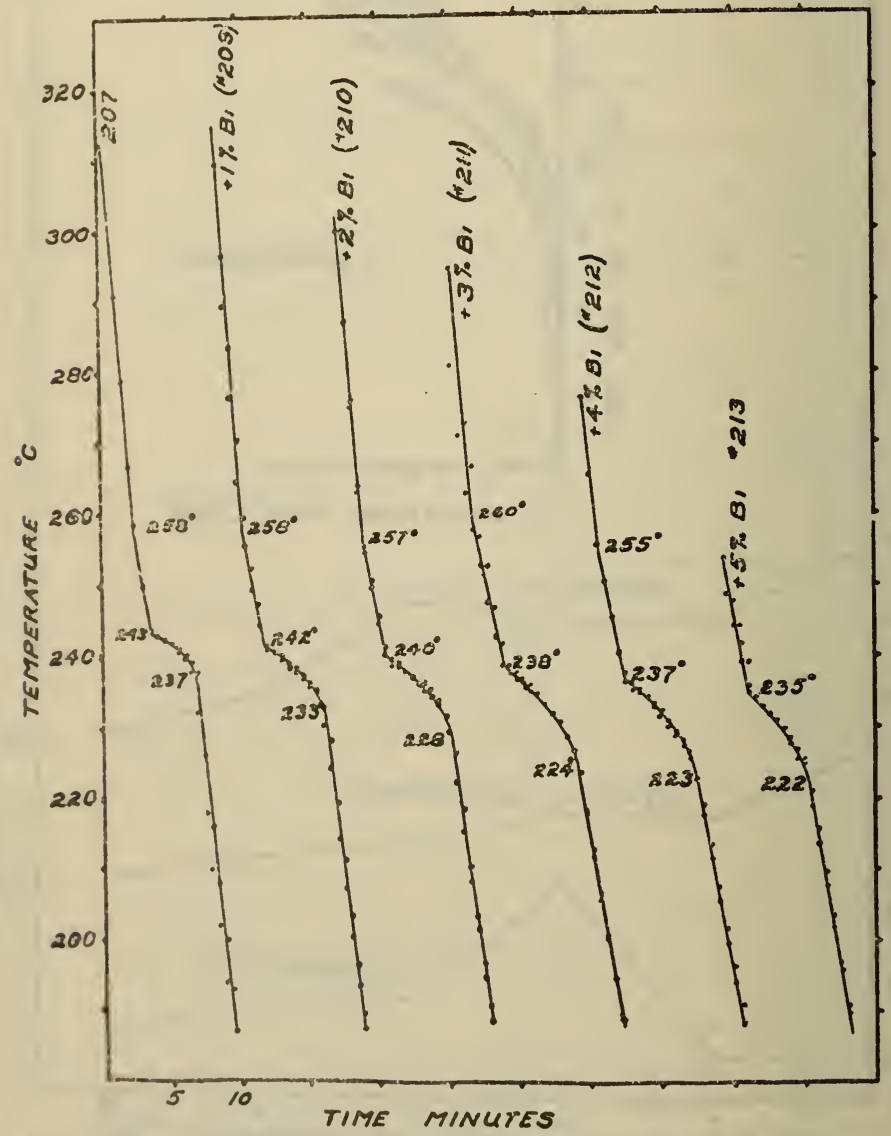

FIGURE 11.-Effect of additions of bismuth on the freezing point of a stereotype metal

established, it might easily be of greater importance than the relatively slight decrease in mechanical properties which accompanies the addition of bismuth. This question could be settled much better in actual printing tests than in the laboratory, and arrangements have been made with the Government Printing Office to run a series of tests to compare the performance in extended printing runs of standard stereotype castings and of the same metal with $1,2,3,4$, and 5 per cent bismuth added. This program has been started and will be reported at a later date. 
The possibility of improved casting properties, including changes in the freezing characteristics, has suggested the possible addition of bismuth to linotype and monotype metals where casting properties and performance in the casting machine are of paramount importance.

\section{FUSIBLE ALLOYS}

Fusible alloys which melt at about the temperature of boiling water usually consist of bismuth, lead, and tin. The addition of a fourth metal, cadmium, produces metallic alloys which are completely molten at temperatures considerably below the boiling point of water. These melting points are unusually low for metallic alloys and have directed attention to these alloys, chiefly as curiosities. The literature of these fusible alloys has been reviewed in a recent publication (14), but there is little information available regarding properties other than the melting points. In addition, there is considerable confusion and contradictory testimony regarding the melting points of the alloys, and particularly regarding the minimum melting possible in the quaternary system bismuth-lead-tin-cadmium.

Parravano and Sirovich (12) in 1912 found that the composition of the quaternary eutectic was 49.5 per cent bismuth, 27.27 per cent lead, 13.13 per cent tin and 10.10 per cent cadmium. They reported that this eutectic melted at $70^{\circ} \mathrm{C}$. Hommel (13) in 1921 reported the eutectic composition to be $50 \mathrm{Bi}: 27 \mathrm{~Pb}: 13 \mathrm{Sn}: 10 \mathrm{Cd}$ with the eutectic arrest at $66^{\circ} \mathrm{C}$. The quaternary eutectic by definition must be the lowest melting alloy in the quaternary system, but in spite of the evidence of Parravano and Sirovich and of Hommel melting points of about $60^{\circ} \mathrm{C}$. are still reported for some of these alloys.

The freezing point curves shown in Figure 12, confirmed the statement of Parravano and Sirovich, that $70^{\circ} \mathrm{C}$. was the minimum melting point for alloys of this quaternary system. These curves were obtained as follows: About $1,000 \mathrm{~g}$ of the alloy in question was melted in a graphite crucible approximately $1 \frac{1}{2}$ inches internal diameter by 5 inches deep. This supplied a pool of molten metal deep enough to permit immersion of the thermometer to the proper depth. The molten metal was superheated to any desired degree and was removed from the source of heat and allowed to cool in the air. During cooling the melt was stirred constantly by means of the thermometer. Temperature readings were taken every 30 seconds and stirring was continued until the mass became almost entirely solid. It was noted that failure to stir or cessation of stirring produced low readings, from 1 to $2^{\circ}$ lower than they should have been. In the curve shown for the eutectic alloy No. 202, Bi 50; Pb 26.7; Sn 13.3; $\mathrm{Cd} 10$, the drop from the $70^{\circ}$ flat to the $69^{\circ}$ flat marks the cessation of stirring. This effect presumably is due to the insulating action of crystals which form on the thermometer bulb and which are mechanically removed during stirring. Incomplete immersion of the thermometer stem also tended to produce low readings and the combination of these two factors may account for some of the melting points lower than $70^{\circ} \mathrm{C}$., which have been reported.

Parravano and Sirovich's conclusions are confirmed by this cooling curve. The eutectic composition, or at least the close approach to eutectic composition, is shown by the absence of a solidification range. No solid crystals were detected until the temperature had 
dropped to $71^{\circ} \mathrm{C}$. The melt became completely solid at $70^{\circ}$ to $69^{\circ}$ C. and no further arrests appeared on cooling to $45^{\circ} \mathrm{C}$. If the composition varies somewhat from the eutectic values, as in alloy No. 202 "off composition" in which only the cadmium varies from the eutectic proportions, most of the solidification still occurs at $70^{\circ} \mathrm{C}$.

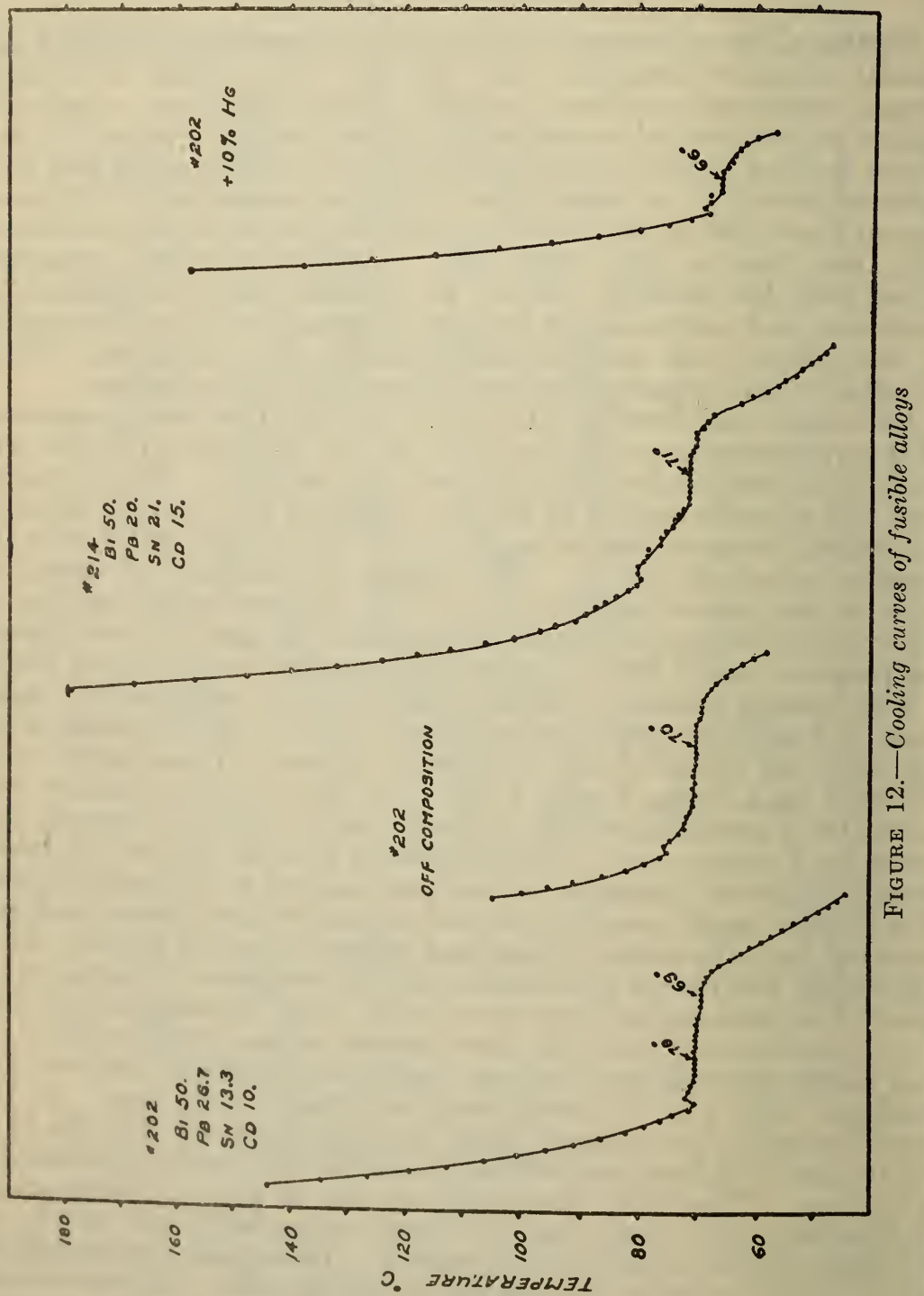

as shown in the second curve in Figure 12, but the curve shows the appearance of a solidification range beginning at $75^{\circ} \mathrm{C}$. If the third will becin tor alloy $\mathrm{No}$. 214, Bi 50; Pb 20; Sn 21; Cd 15; crystals apear at about $90^{\circ} \mathrm{C}$., solidification begins at $80^{\circ} \mathrm{C}$.; 
at $75^{\circ} \mathrm{C}$. it is no longer possible to stir the semisolid mass, and solidification is complete at $70^{\circ} \mathrm{C}$. This particular composition was studied as it was reported (11) to melt at $126^{\circ} \mathrm{F}$. or $52^{\circ} \mathrm{C}$. The fourth curve of the series shows the effect of the addition of 10 per cent, by weight, of mercury on the melting point of the eutectic alloy No. 202. This amount of mercury lowers the solidification point to about $66^{\circ} \mathrm{C}$. It will require, therefore, appreciably more than 10 per cent mercury to lower the melting point to $60^{\circ} \mathrm{C}$.

Some of the mechanical properties of Parravano's eutectic alloy (Wood's metal) and the effect on these properties of the addition of 10 per cent of mercury to the alloy are shown in Table 5.

TABLE 5.-Mechanical properties of very fusible alloys

\begin{tabular}{|c|c|c|c|c|c|}
\hline No. & Composition & $\begin{array}{l}\text { Tensile } \\
\text { strength }\end{array}$ & $\begin{array}{l}\text { Brinell } \\
\text { hardness } \\
\text { number }\end{array}$ & $\begin{array}{l}\text { Elongation } \\
\text { in } 2 \text { inches }\end{array}$ & $\begin{array}{l}\text { Solidifica- } \\
\text { tion point }\end{array}$ \\
\hline $\begin{array}{l}202-\cdots- \\
187-\cdots \\
187\end{array}$ & $\begin{array}{l}\text { Bi } 50: \mathrm{Pb} 26.7: \mathrm{Sn} 13.3: \mathrm{Cd} 10 \\
\text { No. } 202+10 \text { per cent } \mathrm{Hg} \\
\text { Aged } 6 \text { weeks at room temperature }\end{array}$ & $\begin{array}{r}\text { Lb./in. }{ }^{2} \\
5,990 \\
5,970 \\
6,000\end{array}$ & $\begin{array}{r}9.2 \\
8.9 \\
10.0\end{array}$ & $\begin{array}{c}\text { Per cent } \\
140 \\
89 \\
42.5\end{array}$ & $\begin{array}{r}{ }^{\circ} \mathrm{C} . \\
\quad 70 \\
\\
66\end{array}$ \\
\hline
\end{tabular}

These mechanical properties were determined on cast test bars, 0.505 inch in diameter, and each figure given in the table is the average of three determinations. The data show that the tensile strength of the eutectic alloy is not appreciably affected by the addition of 10 per cent mercury, although the Brinell hardness, per cent elongation, and solidification point all are lowered. One of the test bars of No. 202 alloy exhibited remarkable elongation. With the testing machine set for 0.5 inch per minute free travel, the test bar stretched without breaking until the limit of travel of the machine was reached. The original 2 -inch gage length was stretched out to more than 6 inches. Such elongation is unusual in an alloy which approaches eutectic composition. This alloy apparently could be drawn to wire without difficulty. The data also indicate that the addition of mercury produces susceptibility to aging. Six weeks aging at room temperature did not affect the tensile strength of the alloy which contained mercury, but increased the hardness somewhat and decidedly decreased the elongation.

\section{SUMMARY}

Lead-bismuth alloys.-The tensile strength, Brinell hardness, and elongation of lead-bismuth alloys containing from 1 to 50 per cent bismuth were studied. Bismuth hardens lead alloys, throughout the range of composition studied, except for some irregularity in the region of maximum solubility of bismuth in solid lead. Leadbismuth alloys are softer and tougher than alloys which contain corresponding amounts of antimony. This is shown by the fact that lead-bismuth alloys containing 12 per cent bismuth or less, were readily rolled to sheet one-thirty-second inch thick. Neither age hardening nor susceptibility to heat treatment could be detected in the alloys which contained less than 20 per cent bismuth, perhaps because the bulk of the samples was too great for satisfactory response to heat treatment. However, the alloys which contained more than 30 per cent bismuth show some effects of heat treatment. 
Lead-tin alloys. - The tensile strength, hardness and elongation of lead-tin alloys, containing from 5 to 50 per cent tin, have been determined. The data show that the hardening and stiffening action of tin toward lead is of the same order of magnitude as that of bismuth toward lead. An interesting feature of the data is the uniformity of properties of the alloys containing from 30 to 40 per cent tin.

Type metals.-The tensile strength, hardness, elongation, resistance to compression, and solidification characteristics of a number of type metals, with and without additions of bismuth, have been determined. Additions of bismuth tended to decrease slightly the tensile strength, hardness, and resistance to compression of the alloys. Additions of bismuth also modified the solidification characteristics of the alloys, and some indications of improvement in casting properties of the alloys were observed. Additional experiments have been started to see if these two factors are important enough to offset the slight softening effect of bismuth on the alloys.

Fusible alloys. - The conflict of evidence in the literature, regarding the minimum melting point obtainable for fusible alloys of bismuth, lead, tin, and cadmium, is reviewed briefly. Cooling curves are presented to confirm the conclusions of Parravano and Sirovich that $70^{\circ} \mathrm{C}$. is the minimum melting point for these quaternary alloys. Melting points lower than $70^{\circ} \mathrm{C}$. can be obtained by the addition of mercury to the alloys, but in the absence of mercury quaternary alloys of bismuth, lead, tin, and cadmium do not melt below $70^{\circ} \mathrm{C}$. Minor changes in composition of the quaternary eutectic alloy affect the freezing range more noticeably than they affect the final solidification point of the alloy. Unusual elongation values were observed in the case of the quaternary eutectic alloy.

\section{ACKNOWLEDGMENTS}

Thanks are due to B. L. Wehmhoff, of the Government Printing Office, Washington, D. C., and to R. P. Douglas, of the Eastern Chemical Laboratories, New York, N. Y., for the samples of commercial type metals and for cooperation in the type-metal investigation. The author acknowledges his indebtedness to W. C. Smith, of the Cerro de Pasco Copper Corporation, for cooperation in the preparation of specimens and in assembling the data, and to Louis Jordan, of the National Bureau of Standards, for advice throughout the course of the investigation and for assistance in interpreting the results.

\section{BIBLIOGRAPHY}

LEAD-BISMUTH ALLOYS

1. W. Herold, the Binary System Lead-Bismuth, Z. Anorg. Chem., 112, p. $131 ; 1920$.

2. Di Capua and Arnone, Hardness of the Alloys of Lead and Bismuth and of

Cadmium and Bismuth, Atti. Accad. Lincei (5), 33, p. 28; 1924.
3. Dean, Hudson, and Fogler, The System Lead-Antimony, Ind. Eng. Chem., 17, p. $1246 ; 1925$

4. Dean, Zickrick, and Nix, The Lead-Antimony System and Hardening of I.ead Alloys, Trans. A. I. M. M. E., 73, p. 505; 1926.

5. A. Mallock, Hardness of Alloys, Nature, 121, p. 827; 1928.

6. Cowan, Hiers, and Edwards, Constitution of Lead-Bismuth Alloys, A. S. S. T. National Metals Handbook, p. 725; 1030.

7. Bismuth, Bureau of Standards Circular No. 382; 1930. 


\section{LEAD-TIN ALLOYS}

8. Cowan, Hiers, and Edwards, Constitution of Lead-Tin Alloys, A. S. S. T. National Metals Handbook, p. 718; 1930.

TYPE METALS

9. E. Wiedemann, The Volume Changes of Metals and Alloys During Melting, Ann. der Physik, 20, p. 228; 1883.

10. Y. Matuyama, On the Volume Change in Certain Type Metals During Solidification, Sci. Rep. Tohoku Imp. Univ., 17, p. 11; 1928.

\section{FUSIBLE ALLOYS}

11. R. Pearson, A Fusible Electric Circuit Breaker for Fire Alarm Purposes, British Patent No. 23586; 1900.

12. Parravano and Sirovich, Quaternary Alloys of Lead, Cadmium, Bismuth and Tin, Gazz. Chim. Ital., 4.2, I, p. 630; 1912.

13. W. Hommel, Graphic Representation of Three and Four Component Alloys, Zeit. Metallkunde, 13, pp. 456, 511, 565; 1921.

14. The Use of Bismuth in Fusible Alloys, Bureau of Standards Circular No. $388,1930$.

Washington, August 6, 1930. 